\title{
Granulation of gelatine by laminar jet breakup
}

\author{
S.M. Lu, M.N. Shaw, D.J. Lee* \\ Department of Chemical Engineering, National Taiwan University, Taipei 10617, Taiwan \\ Received 3 December 2007; accepted 10 December 2007
}

\begin{abstract}
Granulation of gelatine by the breakup of its laminar jet followed by solidification of the droplets in a solvent has been investigated experimentally. The effects of nozzle size and tank pressure on granulation have been studied. Particles relatively narrow in size distribution were obtained by using small nozzle and low pressure. Particles in two sizes were obtained from nozzles with larger diameters.
\end{abstract}

(C) 2007 Taiwan Institute of Chemical Engineers. Published by Elsevier B.V. All rights reserved.

Keywords: Granules; Jet; Instability; Viscosity

\section{Introduction}

Materials in granule form have the advantages of fluidity, less dust, appealing to sight, and convenience in application when compared with those in the forms of powder, chips, chunks, and others. Depending on the material and the size requirement, different granulation methods are available. One method for producing granules of diameter around $1 \mathrm{~mm}$ is by solidifying the droplets produced by breakup of laminar liquid jet. An example is producing urea beads by prilling. Urea melt, however, is a liquid with low viscosity. For granulation from viscous liquids, further investigation may provide more information (Cramer et al., 2004; Lu et al., 2007; Pan and Suga, 2006; Serra et al., 2007; Zhang et al., 2007).

Granulation of gelatine faces technical challenge (Podczeck et al., 1999; Taha et al., 2000; Von Orelli and Leuenberger, 2004). In view of the fact that gelatine produced is in the forms of flakes, powder, or chips, gelatine was used as the material for studying granulation by the breakup of a viscous laminar jet. In this paper, the effects of nozzle size and back pressure on the size distribution of granules produced will be discussed.

\section{Experiment}

Gelatine-water solution of concentration $40 \%$ by weight was prepared by dissolving gelatine no. 104 of a local

\footnotetext{
* Corresponding author.

E-mail address: djleetw@yahoo.com.tw (D.J. Lee).
}

company in water at $60{ }^{\circ} \mathrm{C}$. Gelatine divided into small amounts was added into water at $60{ }^{\circ} \mathrm{C}$ and the mixture was stirred slowly until the solids were dissolved completely. The solution was poured into a pressure vessel of dimension $105(\mathrm{D}) \times 210(\mathrm{H}) \mathrm{mm}$. Air inclusion during dissolution and pouring is inevitable. The solution in the vessel was degassed at 150 torr and was maintained at $60{ }^{\circ} \mathrm{C}$ for jetting.

By raising the vessel pressure, the solution was forced out the vessel through a nozzle at the bottom. For this investigation, the nozzles were made of hypodermic needles. Dimensions of the nozzles used are shown in Table 1. The back pressure was chosen so to make the jet laminar. Because of jet instability, the jet broke to form droplets. All droplets were received by a solvent contained in a glass cylinder of dimension 97(D) $\times 192(\mathrm{~L}) \mathrm{mm}$. The solvent was maintained at $-10{ }^{\circ} \mathrm{C}$ by a cooling coil immersed in the solvent. At the bottom of the cylinder was a stainless steel funnel by which the partially solidified gelatine may be drained.

The jet flow rate was measured manually before and after each experimental run. Each run took $30 \mathrm{~min}$. The droplets were cooled as they fell through the column. However as they were collected in the funnel at the bottom, the particles continued to release heat. Thus, solvent in the funnel was circulated separately to keep the particles in motion and to remove the residual heat. At the end of a run, the particles were drained from the funnel and were dried at room temperature. They were weighted from time to time until a stable weight was attained. Dried particles were then sieved. 
Table 1

Dimensions of nozzles

\begin{tabular}{lllll}
\hline No. & Needle no. & ID $(\mathrm{mm})$ & OD $(\mathrm{mm})$ & Length $(\mathrm{mm})$ \\
\hline $19 \mathrm{a}$ & 19 & 0.71 & 1.07 & 10 \\
$19 \mathrm{~b}$ & 19 & 0.69 & 1.07 & 10 \\
$21 \mathrm{a}$ & 21 & 0.46 & 0.84 & 10 \\
$21 \mathrm{~b}$ & 21 & 0.46 & 0.84 & 10
\end{tabular}

ID for inside diameter, OD for outside.

\section{Results and discussion}

The viscosity of a gelatine solution was measured by using Brookfield viscometer. Air inclusion may occur with the rotor at high rpm. Air inclusion should be avoided during measurements. Viscosity of the solutions at $60{ }^{\circ} \mathrm{C}$ was measured to be, on the average, at $1000 \mathrm{cP}$ (Table 2). Gelatine-water solution is a non-Newtonian liquid. For a given concentration, the viscosity is also dependent on how the solution has been treated since it was prepared. For $40 \mathrm{wt} . \%$ solution, the solution must be heated for it to flow. Prolonged heating or repeated heating and cooling could result in reduced viscosity. For laboratory experiment, it is desirable that each

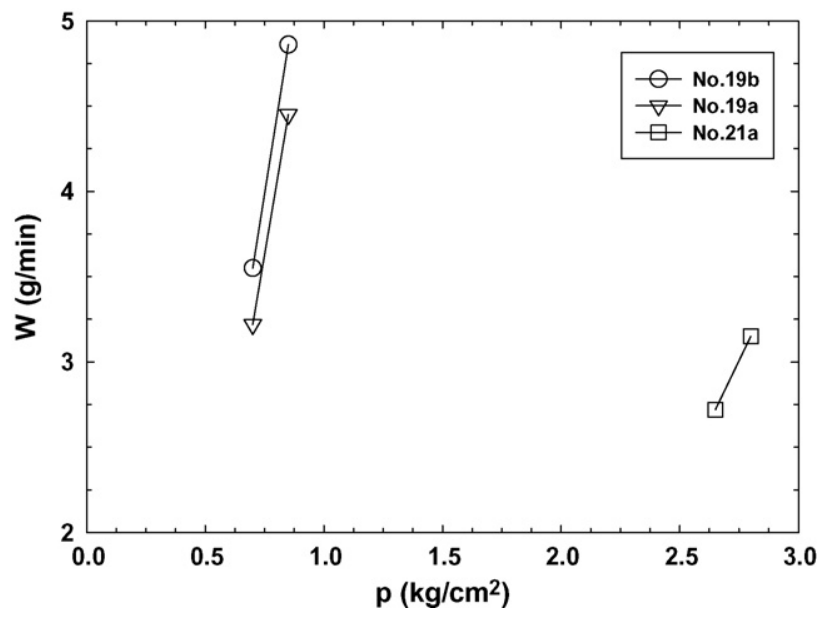

Fig. 1. Mass flow rate versus back pressure plot.

experimental run, from preparation of solution to degassing and jetting, be conducted in an unbroken sequence.

Granulation from gelatine solution at very high concentration is not desirable in that high viscosity results in erratic jet breakup. Viscosity may be decreased by raising the temperature
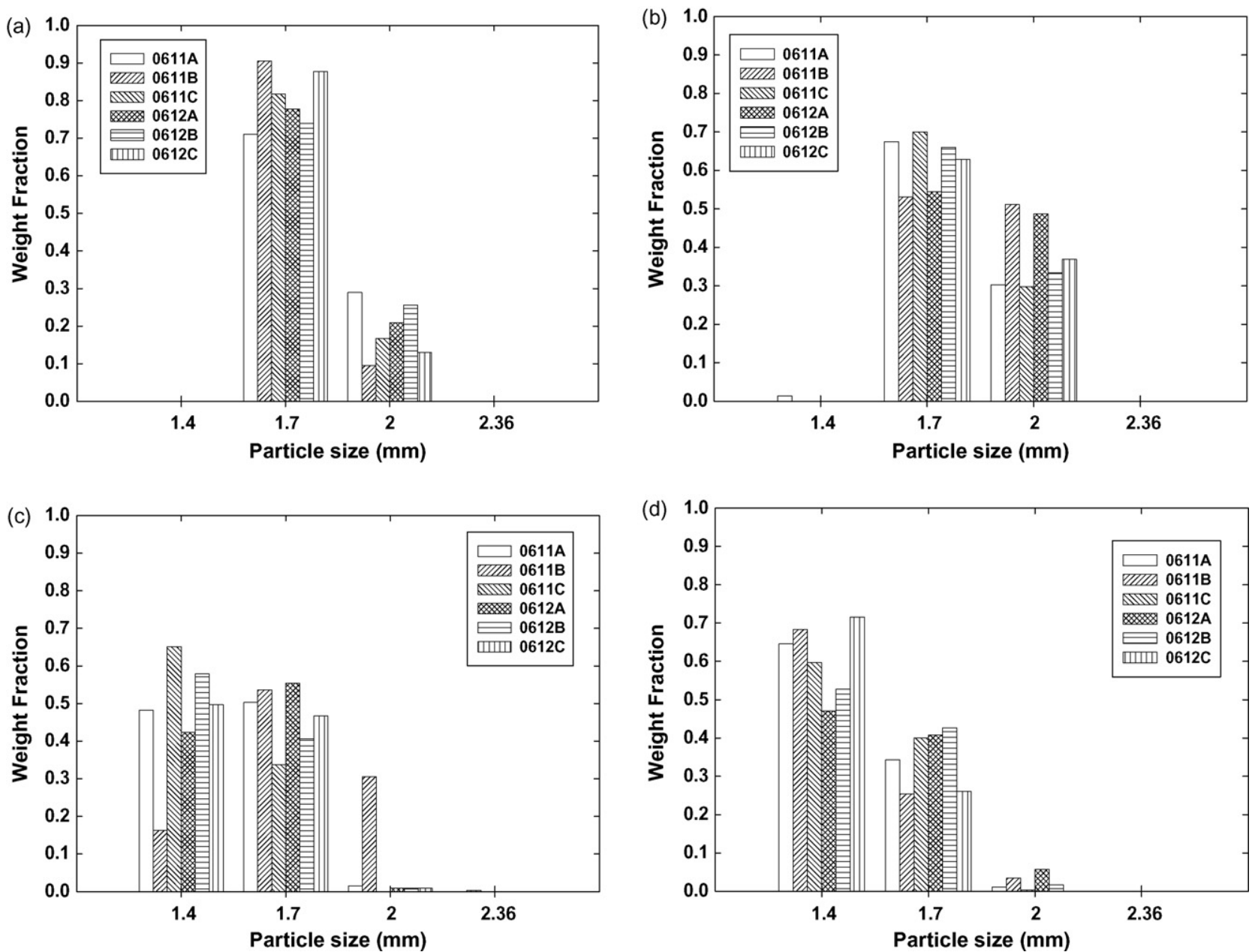

Fig. 2. Weight fraction versus particle size plot. Repeated tests. (a) With no. 19 a needle and pressure $0.7 \mathrm{~kg} / \mathrm{cm}^{2}$, (b) no. $19 \mathrm{~b}$ needle and pressure $0.7 \mathrm{~kg} / \mathrm{cm}^{2}$, (c) no. $19 \mathrm{a}$ needle and pressure $0.85 \mathrm{~kg} / \mathrm{cm}^{2}$, (d) no. $19 \mathrm{~b}$ needle and pressure $0.85 \mathrm{~kg} / \mathrm{cm}^{2}$ 
Table 2

Viscosity (cP) of gelatine-water solution, $40 \%$ by weight, spindle \#3

\begin{tabular}{llc}
\hline$T\left({ }^{\circ} \mathrm{C}\right)$ & rpm & Viscosity $(\mathrm{cP})$ \\
\hline 45 & 12 & 1440 \\
45 & 30 & 1200 \\
45 & 60 & 1395 \\
50 & 12 & 1325 \\
50 & 30 & 1295 \\
50 & 60 & 1280 \\
55 & 12 & 1255 \\
55 & 30 & 1225 \\
55 & 60 & 1195 \\
60 & 12 & 1020 \\
60 & 30 & 1001 \\
60 & 60 & 976 \\
65 & 12 & 1080 \\
65 & 30 & 918 \\
65 & 60 & 903 \\
\hline
\end{tabular}

of the solution. However, increase in temperature is limited by the need to assure the quality of gelatine.

The back pressures used in the experiments were: $0.85,0.8$, and $0.7 \mathrm{~kg} / \mathrm{cm}^{2}$ for no. 19 needles; and 2.8 and $2.65 \mathrm{~kg} / \mathrm{cm}^{2}$ for no. 21 needles. Pressures too low will result in dripping and large droplets; and too high, in turbulent jet. Jet breakup lengths may be as short as $10 \mathrm{~mm}$ at low back pressures. In most experiments, breakup lengths were maintained at around $40 \mathrm{~mm}$. When the nozzle and the back pressure are given, variation in the temperature of the solution will be reflected by the jet. The jet is also affected by air trapped inside the solution. Both breakup length and flow rate will be reduced.

Mass flow rates of the solution under different pressure are shown in Fig. 1. The Reynolds number was found to be in the range of $0.08-0.25$, and the discharge coefficients of the nozzles, 0.004-0.02. Discharge coefficients for present setup were far smaller then those often used for an orifice $(0.6-0.8)$.

Size distributions of the gelatine granules obtained are as follows. With no. 19 needles and pressure $0.7 \mathrm{~kg} / \mathrm{cm}^{2}$, the major size of the granules obtained were found to be in 10/12 mesh (openings 2.0/1.7 mm) and 8/10 mesh $(2.36 / 2.0 \mathrm{~mm}$ ), as shown in Fig. 2(a) and (b); and with pressure $0.85 \mathrm{~kg} / \mathrm{cm}^{2}$, the major size were $12 / 14$ mesh $(1.7 / 1.4 \mathrm{~mm})$ and $8 / 10$ mesh, as shown in Fig. 2(c) and (d). With no. 21 a needle and pressure $2.65 \mathrm{~kg} / \mathrm{cm}^{2}$, nearly $95 \%$ of the granules obtained were found to be in $10 / 12$ mesh; and with no. $21 \mathrm{~b}$ needle and pressure $2.80 \mathrm{~kg} / \mathrm{cm}^{2}$, around $90 \%$ were in 12/14 mesh. These are shown in Fig. 3.

Thus, with larger needles, particles obtained have more than one major size. For a given nozzle, lower back pressure results in larger particles. Smaller needle results in particles more uniform in size. With the nozzle and the pressure both small, relatively uniform large particles may be obtained. Stability of the pressure is important for obtaining granules of the same size. Experiments with fluctuating pressure resulted in granules of a wide size distribution. Thus, the magnitudes and stabilities of the pressure and the temperature as well as the dimensions of the nozzle are factors that may be used to control the size and size distribution of the granules.
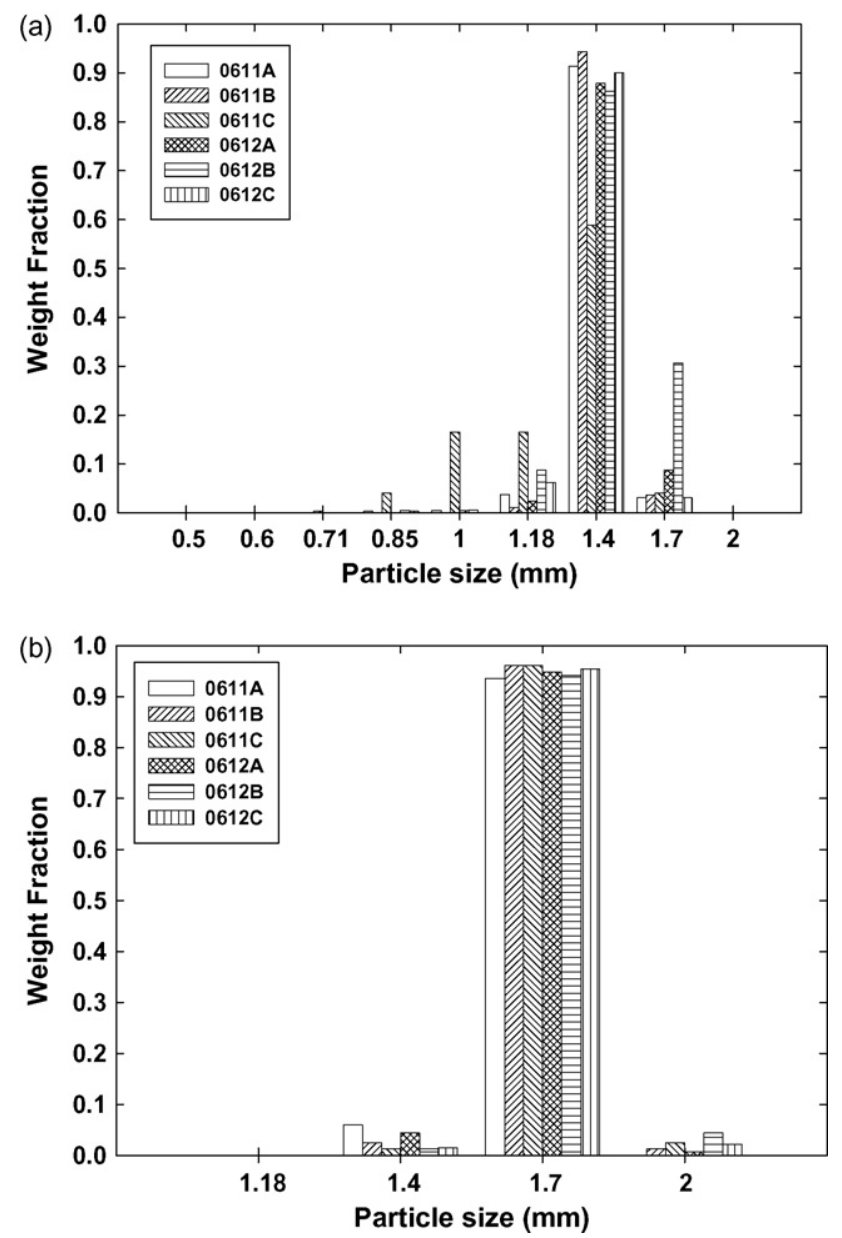

Fig. 3. Weight fraction versus particle size plot. Repeated tests. (a) With no. 21a needle and pressure $2.65 \mathrm{~kg} / \mathrm{cm}^{2}$, (b) no. $21 \mathrm{~b}$ needle and pressure $2.80 \mathrm{~kg} / \mathrm{cm}^{2}$.

\section{Conclusions}

From granulation of gelatine by laminar jet breakup, the following conclusions were obtained. Magnitude and stability of the backup pressure and the dimensions of nozzle are most important for obtaining relatively uniform granules. Small needle results in granules relatively large and uniform in size. Large needle results in granules that have more than one major size. For granulation of gelatine by laminar jet breakup, the solution at concentration $40 \mathrm{wt} . \%$ and temperature $60{ }^{\circ} \mathrm{C}$ is appropriate.

\section{References}

Cramer, C., P. Fischer, and E. J. Windhab, "Drop Formation in a Co-flowing Ambient Fluid," Chem. Eng. Sci., 59, 3045 (2004).

Lu, S. M., S. L. Chang, W. Y. Ku, and H. C. Chang, "Urea Release Rate from a Scoop of Coated Pure Urea Beads. Unified Extreme Analysis," J. Chin. Inst. Chem. Engrs., 38, 295 (2007).

Pan, Y. and K. Suga, "A Numerical Study on the Breakup Process of Laminar Liquid Jets into a Gas," Phys. Fluid, 18, 5, 052101 (2006).

Podczeck, F., S. Blackwell, M. Gold, and J. M. Newton, "The Filling of Granules into Hard Gelatine Capsules," Int. J. Pharm., 188, 59 (1999).

Serra, C., N. Berton, M. Bouquey, L. Prat, and G. Hadziioannou, "A Predictive Approach of the Influence of the Operating Parameters on the Size of 
Polymer Particles Synthesized in a Simplified Microfluidic System," Langmuir, 23, 7745 (2007).

Taha, M. O., K. M. Aiedeh, and B. Amro, "Investigation of the Suitability of Chitosan-triethyleneglycol-phthalate as a Matrix in Prolonged-release, Potentially Orally Administered, Chlorpheniramine Maleate Granules," STP Pharm. Sci., 10, 395 (2000).
Von Orelli, J. and H. Leuenberger, "Search for Technological Reasons to Develop a Capsule or a Tablet Formulation with Respect to Wettability and Dissolution," Int. J. Pharm., 287, 135 (2004).

Zhang, J., X. H. Li, D. J. Zhang, and Z. L. Xiu, “Theoretical and Experimental Investigations on the Size of Alginate Microspheres Prepared by Dropping and Spraying," J. Microencapsul., 24, 303 (2007). 